\title{
Perinatal health care access, childbirth concerns, and birthing decision-making among pregnant people in California during COVID-19
}

Mackenzie D. M. Whipps", Jennifer E. Phipps and Leigh Ann Simmons

\begin{abstract}
Background: During public health emergencies, including the COVID-19 pandemic, access to adequate healthcare is crucial for providing for the health and wellbeing of families. Pregnant and postpartum people are a particularly vulnerable subgroup to consider when studying healthcare access. Not only are perinatal people likely at higher risk for illness, mortality, and morbidity from COVID-19 infection, they are also at higher risk for negative outcomes due to delayed or inadequate access to routine care.
\end{abstract}

Methods: We surveyed 820 pregnant people in California over two waves of the COVID-19 pandemic: (1) a 'nonsurge' wave (June 2020, $n=433$ ), and (2) during a 'surge' in cases (December 2020, $n=387$ ) to describe current access to perinatal healthcare, as well as concerns and decision-making regarding childbirth, over time. We also examined whether existing structural vulnerabilities - including acute financial insecurity and racial/ethnic minoritization - are associated with access, concerns, and decision-making over these two waves.

Results: Pregnant Californians generally enjoyed more access to, and fewer concerns about, perinatal healthcare during the winter of 2020-2021, despite surging COVID-19 cases and hospitalizations, as compared to those surveyed during the COVID-19 'lull' in the summer of 2020. However, across 'surge' and 'non-surge' pandemic circumstances, marginalized pregnant people continued to fare worse - especially those facing acute financial difficulty, and racially minoritized individuals identifying as Black or Indigenous.

Conclusions: It is important for clinicians, researchers, and policymakers to understand whether and how shifting community transmission and infection rates may impact access to perinatal healthcare. Targeting minoritized and financially insecure communities for increased upstream perinatal healthcare supports are promising avenues to blunt the negative impacts of the COVID-19 pandemic on pregnant people in California.

Keywords: COVID-19, SARS-CoV-2, Pregnancy, Perinatal, Healthcare access, Childbirth, Decision-making, California, Racial/ethnic minoritization, Financial insecurity

\footnotetext{
* Correspondence: mdwhipps@ucdavis.edu

Department of Human Ecology, Perinatal Origins of Disparities Center,

University of California, Davis, California, USA
}

C C The Author(s). 2021 Open Access This article is licensed under a Creative Commons Attribution 4.0 International License, which permits use, sharing, adaptation, distribution and reproduction in any medium or format, as long as you give appropriate credit to the original author(s) and the source, provide a link to the Creative Commons licence, and indicate if changes were made. The images or other third party material in this article are included in the article's Creative Commons licence, unless indicated otherwise in a credit line to the material. If material is not included in the article's Creative Commons licence and your intended use is not permitted by statutory regulation or exceeds the permitted use, you will need to obtain permission directly from the copyright holder. To view a copy of this licence, visit http://creativecommons.org/licenses/by/4.0/ The Creative Commons Public Domain Dedication waiver (http://creativecommons.org/publicdomain/zero/1.0/) applies to the data made available in this article, unless otherwise stated in a credit line to the data. 


\section{Introduction and background}

Healthcare access is a crucial barometer of population wellbeing worldwide. The ability to access care when one is ill, injured, or otherwise in need of medical support is a necessary condition for a community to survive and thrive in the twenty-first century [1]. During public health emergencies, whether a natural disaster, a severe economic downturn, or a pandemic, access to adequate healthcare remains an important metric to measure, and ultimately, an important lever for intervention [2].

The World Health Organization (WHO) officially declared the outbreak of COVID-19, the illness caused by the novel respiratory virus SARS-CoV-2, to be a pandemic on March 11th, 2020 [3]. Since that time, COVID-19 infection rates have increased exponentially across the world [4]. As of this writing, the nation with the highest infection rate by far is the United States: on June 1st of 2020, the United States had confirmed 1.8 million cases and 108,500 fatalities, and 6 months later, on December 1st, that number had grown to 13.8 million confirmed cases with 270,800 fatalities [5]. Healthcare systems across the country have been stretched to their limits. Personal protective equipment was scarce. Providers were working longer hours and more consecutive shifts while managing more complicated and critical cases. Patients were being doubled up in single rooms, boarded in makeshift rooms and hallways, or in the worst cases, being turned away from hospitals due to the lack of space, personnel, and equipment resources.

The locations of viral epicenters within the United States have shifted over time in response to a number of factors, including state and local public health policy initiatives to curb the transmission of COVID-19 in community hotspots. While New York City and other dense, urban areas were initial epicenters, infections have gradually spread to more remote areas. Rural and suburban areas are now over-represented in terms of both overall cases and fatalities $[5,6]$.

The state of California, in particular, is unique in this respect. With over 40 million residents, California was the first US state to impose strict 'lockdown' measures to curb COVID-19 outbreaks and prevent their spread to other areas [7]. On March 16th, only 5 days after the WHO declared COVID-19 a pandemic, the governor of California issued a shelter-in-place order for 6 counties; that order was extended statewide on March 19th [8]. These early measures were largely considered successful. Early adoption seems to have been more effective in terms of reductions in cases as compared to delayed action [9], and simulations have estimated that nearly 1500 deaths were averted in just the first 4 weeks of enactment, when case rates were still very low throughout the state [10]. By early May, many cities and counties in California began relaxing restrictions, with county-level infection rates holding steady or rising slowly throughout the summer and autumn of 2020 [5]. However, on December 3rd, statewide region-by-region shelter-inplace orders were reinstated as the state of California passed 1.25 million COVID-19 cases [8]. Hospitalizations soon reached an all-time high in the state, and capacity in intensive care units fell to dangerously low levels [11]. These ebbs and flows of case rates and associated hospitalizations over time - so-called 'surges' - represent specific historical and geographic contexts within which healthcare access in emergencies can be studied in-depth.

Pregnant people are a particularly vulnerable subgroup to consider when studying healthcare access in emergencies. Not only are pregnant people likely at higher risk for illness, mortality, and morbidity from COVID-19 infection $[12,13]$, they are also at higher risk for negative outcomes due to delayed or inadequate access to routine care. Timely and appropriate perinatal care from a qualified health professional is one of the primary determinants of a healthy pregnancy, a healthy birth, and later health outcomes for birthing people and their children $[14,15]$. However, studies conducted during previous viral outbreaks have shown that barriers to healthcare utilization - especially reproductive and maternal/child healthcare - increase dramatically during public health emergencies [16]. During times of health crisis, such as a local 'surge' of infection during a pandemic, it is crucial that health practitioners and policy makers understand whether the healthcare needs of pregnant people are being met, whether other factors related to inequitable access to healthcare are being compounded by the acute crisis, and how best to support this vulnerable population.

Research is only just beginning to explore the indirect effects of the 2020-2021 COVID-19 pandemic on perinatal healthcare access and quality. Researchers in Europe and the United States have found increased concerns about perinatal health among pregnant people, including increased feelings of fear and worry and higher rates of pregnancy-related anxiety $[17,18]$. Qualitative work with pregnant women in Turkey found that women reported skipping planned prenatal appointments and putting their prenatal care 'on hold' while the pandemic raged around them [19]. Some women also reported shifting plans for the birth of their child in response to increasing rates of COVID-19 in their local hospital [19].

In the United States, researchers who have surveyed healthcare providers have similarly found that pregnant people are expressing intense fear of contracting COVID-19 in a hospital setting [20]. Providers report reducing the number of prenatal visits, shifting to telemedicine-based prenatal care, and asking patients to 
take over responsibility for tracking vital health markers like blood pressure [20]. Like in Turkey, US providers and pregnant people also report a substantial increase in the number of pregnant people exploring childbirth options that limit their exposure to hard-hit local hospitals, including midwife-attended homebirths, birth-center births, and unattended 'freebirths' [17, 20]. Many healthcare providers postulate that this shift reflects a fear of the hospital and associated risk for contracting COVID19 rather than a real desire for an out-of-hospital birth $[20,21]$. Though out-of-hospital birth can be as safe as in-hospital births (and perhaps even safer than inhospital births for certain low-risk individuals [22, 23]), it is generally recognized by home-birth and hospitalbirth providers alike that planning an out-of-hospital birth out of fear or panic caused by rising rates of infection, or switching to a homebirth late in pregnancy, is not ideal $[20,21]$.

Pandemic-related worry and lower access to perinatal healthcare has been shown to be especially pronounced among minoritized and/or marginalized individuals [24]. These same populations also generally face increased barriers to accessing adequate perinatal care in high-income countries, even before the added obstacles of a public health emergency [25]. Understanding whether and how local infection rates and existing marginalization may interact to produce these worries, perceptions, and decisions regarding perinatal healthcare, especially in a locality with some of the most extreme COVID-19 infection rates in the world, is an important next step.

\section{Current study}

Given the importance of perinatal healthcare access to family and community health, this study sought to describe the context of adversity facing pregnant people over 2 distinct timepoints during the 2020-2021 COVID-19 pandemic in California: a summer 'nonsurge' wave and a winter 'surge' wave. We also sought to explore whether perinatal healthcare access, concerns, and decisions were different for subgroups with further vulnerabilities, including minoritized people and people facing acute financial difficulty. We undertook three specific aims toward these ends:

Aim 1. Describe overall rates and changes in rates of self-reported access to prenatal healthcare in California over 2 time points during the 2020-2021 COVID-19 pandemic.

Aim 2. Describe whether and how concerns and decision-making regarding childbirth have changed over 2 time points during the 2020-2021 COVID-19 pandemic.

Aim 3. Explore whether these adverse perinatal healthcare experiences differ by racial/ethnic minoritization and by individual levels of financial strain.

\section{Methods}

\section{Participants}

Our team surveyed pregnant Californians crosssectionally using two web-based surveys. Wave 1 data were collected from June 6th to July 29th of 2020, while Wave 2 data were collected from December 24th 2020 to January 27th 2021. The recruitment materials and surveys were available in both English and Spanish, which are the top two most spoken languages in the state. Participants took approximately $20-30 \mathrm{~min}$ to complete the survey and were offered a gift card for their participation. We solicited participants using targeted social media campaigns (e.g., on Facebook, Instagram, Twitter) describing the study in English and Spanish and featuring diverse images of pregnant people and couples. Participants were considered eligible if they resided in California, were between ages 18 and 45 years, and were currently pregnant. Informed consent was obtained via electronic signature. Ethics approval was provided prior to the start of the study by University of California, Davis' Institutional Review Board. All methods, including informed consent procedures, were carried out in accordance with the Declaration of Helsinki - Ethical Principles for Medical Research Involving Human Subjects.

\section{Missing data}

Several strategies to ensure high data quality were employed for this web-based survey. Participants who did not reach the end of the survey instrument, completed the survey in less than $10 \mathrm{~min}$, or attempted to take the survey multiple times had their data removed for analysis. Participant age was asked twice, once at the beginning of the survey and once at the end; any participant without matching responses for these two items was removed from analyses. In all, 216 participants were not included in the analytic sample as a result of these quality checks (155 out of 588 in Wave 1 and 62 out of 454 in Wave 2). Sporadic missingness was handled using list-wise deletion.

\section{Measures}

All survey items within the questionnaire can be found in the supplementary file.

\section{Prenatal healthcare access}

Four items assessed participants' current access to prenatal healthcare experiences. Participants were asked: "Has your provider started doing remote visits, such as using video or telephone?" (responses were dichotomous, yes/no) and "Has your provider reduced the number of visits?" (responses were dichotomous, yes/no). For both items, participants also had the option to select "I don't know" and "I prefer not to answer". 
Participants also were asked to respond to the following prompt to assess how often and for what reasons they accessed healthcare during their prenatal period: "Please rate the following statements in terms of how you have been doing for the last 7 days." These items were: "I seek care for health problems not related to my pregnancy" and "I schedule an extra visit with my prenatal provider if I am concerned about my pregnancy". Response options were a Likert-type, behaviorally anchored scale which ranged from 0 to 4: 0 - Never, 0 days; 1 - Rarely, 1-2 days; 2 - Sometimes, 3-4 days, 3 - Often, 5-6 days, and 4 - Always, 7 days. Participants also had the option to select "Does not apply" and "I prefer not to answer".

\section{Concerns about childbirth healthcare access}

Similar to previous items, participants reported how often they were worried or concerned about the following issues related to their childbirth: "I worry that I will not have my birth support person with me in the delivery room"; "I worry that my provider or health care team will not be available during my delivery"; and "I worry that my healthcare team will not have the equipment and resources they need to support my delivery". As above, response options ranged from 0 (Never) to 4 ( $\mathrm{Al}$ ways) and were treated as continuous in analyses. A measure of Cumulative Concerns about Childbirth Healthcare Access was also created by summing responses to the three individual concerns; the range of the cumulative measure was $0-12$.

\section{Childbirth decision-making}

One item asked participants to report how often they considered having an out-of-hospital birth for their current pregnancy ("I am thinking about not having my baby in a hospital"), again with response options ranging from 0 (Never) to 4 (Always). Participants also were asked whether they had planned to give birth outside of the hospital (yes, no, prefer not to answer) and if so, where (home, birth center, other). Those participants who indicated that they were planning an out-ofhospital birth were then prompted to respond to the following question: "Did COVID-19 change your plans for where to deliver your baby?" (yes, no, prefer not to answer).

\section{Racial/ethnic Minoritization}

Racial/ethnic minoritization, a structural variable that seeks to index exposure to racism and discrimination based on being a visible minority in a white supremacist culture, was conceptualized in a number of ways. At its most broad, we operationalized minoritization as holding a non-white and non-Hispanic identity. Therefore, white participants are compared against those who identify as people of color (POC), and non-Hispanic participants are compared to Hispanic participants. Exploratory analyses also broke down the larger category of 'racially minoritized' into specific racial categories: 1 Black / African-American only, 2 - American Indian / Indigenous / First Nations only, 3 - Asian / AsianAmerican / Native Hawaiian / Pacific Islander only, 5 Some other race only, and 6 - Multiracial. There was an inadequate number of Native Hawaiian and Pacific Islanders to analyze separately as their own group, thus they were grouped with Asians and Asian Americans.

\section{Financial insecurity}

Financial insecurity was operationalized using a single survey item, which asked participants "During the past 2 months, how much difficulty have you had paying your bills?". Responses ranged from 1 to 5 , with the following anchors: 1 - No difficulty at all; 2 - A little difficulty; 3 - Some difficulty; 4 - Quite a bit of difficulty; and 5 - A great deal of difficulty. Participants also had the option to select "I prefer not to answer". Responses are treated as continuous in analyses.

\section{Data analysis}

\section{Access, concerns, and decision-making across waves}

First, we described access, concerns, and decisionmaking across data collection waves. We conducted $\chi^{2}$ tests and univariate regressions to test for differences by wave. We hypothesized that measures of access would decrease, and measured concern would increase, during times of 'surge' (the winter wave). We did not have directional hypotheses with regard to childbirth decisionmaking (i.e., planning or considering an out-of-hospital birth).

\section{Differences by racial/ethnic minoritization and financial insecurity}

First, we examined correlations between the constructs of interest for each wave of data collection. Next, we utilized multivariate regression-based analyses to predict our outcomes of interest (access, concerns, and decision-making) from our predictors of interest: racial/ ethnic minoritization and financial insecurity on a combined sample that included both waves of data, controlling for participant age, primiparity, urbanicity, and essential worker status. Sensitivity analyses were conducted to ascertain whether these relationships differed by data wave. Finally, we descriptively probed the findings on childbirth concerns plotting the cumulative measure of childbirth concerns across wave, ethnic minoritization, level of financial insecurity, and racialized identities. Given the small absolute numbers of participants within each of the specific categories - especially within each racial and financial insecurity subgroup - 
these further analyses are considered exploratory and hypothesis testing was not conducted.

\section{Results}

The analytic samples of pregnant Californians are comprised of 433 participants for wave 1 (summer 2020) and 387 participants for wave 2 (winter 2020-2021). See Table 1 for demographic characteristics of analytic samples in both data waves. Samples are similar across waves, with some small differences: wave 2 participants are on average $\sim 1$ year older, earlier in their pregnancies, more likely to be essential workers, and live in more urban contexts than wave 1 participants. Race and ethnicity demographics for this sample are very similar to the demographic makeup of California at large [26].

\section{Access, concerns, and decision-making across waves}

Table 2 shows the results for access, concerns, and decision-making across waves. We found that prenatal healthcare access was overall better during wave 2 (the winter 'surge') than during wave 1 . Fewer participants reported that their provider had reduced the number of

Table 1 Demographic characteristics across data collection wave

\begin{tabular}{|c|c|c|}
\hline Characteristic & $\begin{array}{l}\text { June-July } 2020 \\
n=433 \\
\mathrm{~N}(\%)\end{array}$ & $\begin{array}{l}\text { December 2020-January } 2021 \\
n=387 \\
\mathrm{~N}(\%)\end{array}$ \\
\hline \multicolumn{3}{|l|}{ Maternal age } \\
\hline $18-24$ & $53(12.2)$ & $27(7.0)$ \\
\hline $25-34$ & $255(58.9)$ & $224(57.9)$ \\
\hline $35+$ & $125(28.9)$ & $136(35.1)$ \\
\hline \multicolumn{3}{|l|}{ Participant is essential worker } \\
\hline Yes & $103(23.8)$ & $149(38.5)$ \\
\hline No & $112(25.9)$ & $84(21.7)$ \\
\hline Not currently employed / no answer & $218(50.3)$ & $154(39.8)$ \\
\hline \multicolumn{3}{|l|}{ Ethnicity } \\
\hline Hispanic & $149(34.4)$ & $151(39.0)$ \\
\hline Not Hispanic & $280(64.7)$ & $236(61.0)$ \\
\hline \multicolumn{3}{|l|}{ Race } \\
\hline White & $233(53.8)$ & $199(51.4)$ \\
\hline Black / African American & $20(4.6)$ & $18(4.7)$ \\
\hline Indigenous / First Nations & $4(.9)$ & $2(.5)$ \\
\hline Asian / Pacific Island / Native Hawaiian & $36(8.3)$ & $37(9.6)$ \\
\hline Other race & $37(8.6)$ & $42(10.9)$ \\
\hline Multiracial & $82(18.9)$ & $64(16.5)$ \\
\hline \multicolumn{3}{|l|}{ Urbanicity } \\
\hline Rural & $22(5.1)$ & $14(3.7)$ \\
\hline Semi-rural & $51(11.8)$ & $33(8.6)$ \\
\hline Suburban & $191(44.1)$ & $162(42.3)$ \\
\hline Urban & 99 (22.9) & $85(22.2)$ \\
\hline Major metropolitan & $63(14.6)$ & $89(23.2)$ \\
\hline \multicolumn{3}{|l|}{ Trimester of pregnancy } \\
\hline 1st (0-13 weeks+ 6 days) & $96(22.2)$ & $121(31.3)$ \\
\hline 2nd (14-27 weeks+ 6 day) & $188(43.4)$ & $172(44.4)$ \\
\hline 3rd (28-42 weeks) & $142(32.8)$ & $94(24.2)$ \\
\hline No answer / unsure & $7(1.6)$ & $0(.0)$ \\
\hline \multicolumn{3}{|l|}{ Parity } \\
\hline Primipara & $206(47.6)$ & $183(47.4)$ \\
\hline Multipara & $227(52.4)$ & $203(52.6)$ \\
\hline
\end{tabular}

Every participant did not respond to every item; therefore Ns do not necessarily sum to total analytic sample size 
Table 2 Snapshot of healthcare access, childbirth concerns, and childbirth decision-making across data collection wave

\begin{tabular}{|c|c|c|c|c|}
\hline & $\begin{array}{l}\text { June-July } 2020 \\
n=433 \\
\mathrm{~N}(\%)\end{array}$ & $\begin{array}{l}\text { December 2020-January } 2021 \\
n=387 \\
\mathrm{~N}(\%)\end{array}$ & $p$-value & Sig. \\
\hline \multicolumn{5}{|l|}{ Prenatal healthcare access } \\
\hline Provider has begun remote visits & & & 0.10 & \\
\hline Yes & $190(43.9)$ & $148(38.2)$ & & \\
\hline No & $191(44.1)$ & $175(45.2)$ & & \\
\hline Unsure / no answer & $52(12.0)$ & $64(16.5)$ & & \\
\hline Provider has reduced number of prenatal visits & & & $<0.001$ & $* * *$ \\
\hline Yes & $147(34.0)$ & $90(23.3)$ & & \\
\hline No & $209(48.3)$ & $183(47.3)$ & & \\
\hline Unsure / no answer & $77(17.8)$ & $114(29.5)$ & & \\
\hline I seek care for health issues outside pregnancy & & & 0.02 & * \\
\hline Always & $46(10.6)$ & $43(11.1)$ & & \\
\hline Sometimes / Often & $108(24.9)$ & $122(31.5)$ & & \\
\hline Rarely / Never & $240(55.4)$ & $186(48.1)$ & & \\
\hline Does not apply / I don't know & $39(9.0)$ & $36(9.3)$ & & \\
\hline I schedule extra prenatal visits if concerned & & & 0.06 & t \\
\hline Always & $60(13.9)$ & $57(14.7)$ & & \\
\hline Sometimes / Often & $75(17.3)$ & $85(22.0)$ & & \\
\hline Rarely / Never & $231(53.4)$ & $183(47.3)$ & & \\
\hline Does not apply / I don't know & $67(15.5)$ & $62(16.0)$ & & \\
\hline \multicolumn{5}{|l|}{ Concerns about childbirth healthcare access } \\
\hline I worry about missing support person during birth & & & $<0.001$ & $* * *$ \\
\hline Always & 89 (20.6) & $65(16.8)$ & & \\
\hline Sometimes / Often & $208(48.0)$ & $143(37.0)$ & & \\
\hline Rarely / Never & $130(30.0)$ & $169(43.7)$ & & \\
\hline Does not apply / I don't know & $6(1.4)$ & $10(2.6)$ & & \\
\hline I worry about provider being unavailable during birth & & & 0.82 & \\
\hline Always & $19(4.4)$ & $19(4.9)$ & & \\
\hline Sometimes / Often & $121(27.9)$ & $99(25.6)$ & & \\
\hline Rarely / Never & $281(64.9)$ & $252(65.1)$ & & \\
\hline Does not apply / I don't know & $12(2.8)$ & $17(4.4)$ & & \\
\hline I worry provider won't have resources during birth & & & 0.82 & \\
\hline Always & $16(3.7)$ & $18(4.7)$ & & \\
\hline Sometimes / Often & $90(20.8)$ & $80(20.7)$ & & \\
\hline Rarely / Never & $320(73.9)$ & $276(71.3)$ & & \\
\hline Does not apply / I don't know & $7(1.6)$ & $13(3.4)$ & & \\
\hline \multicolumn{5}{|l|}{ Childbirth decision-making } \\
\hline I am thinking about not having my baby in a hospital & & & 0.06 & t \\
\hline Always & $21(4.9)$ & $15(3.9)$ & & \\
\hline Sometimes / Often & $52(12.0)$ & $33(8.5)$ & & \\
\hline Rarely / Never & $338(78.1)$ & $319(82.4)$ & & \\
\hline Does not apply / I don't know & $22(5.1)$ & $20(5.2)$ & & \\
\hline Planned location of birth & & & 0.35 & \\
\hline Hospital & $402(92.8)$ & $368(95.6)$ & & \\
\hline
\end{tabular}


Table 2 Snapshot of healthcare access, childbirth concerns, and childbirth decision-making across data collection wave (Continued)

\begin{tabular}{|c|c|c|c|c|}
\hline & $\begin{array}{l}\text { June-July } 2020 \\
n=433 \\
\mathrm{~N}(\%)\end{array}$ & $\begin{array}{l}\text { December 2020-January } 2021 \\
n=387 \\
\mathrm{~N}(\%)\end{array}$ & $p$-value & Sig. \\
\hline Birth center & $19(4.4)$ & $12(3.1)$ & & \\
\hline Homebirth & $6(1.4)$ & $3(.8)$ & & \\
\hline Unsure / no answer & $6(1.4)$ & $2(.5)$ & & \\
\hline COVID-19 changed my plans for where to give birth ${ }^{\text {a }}$ & & & 1.00 & \\
\hline Changed plans to birth center & $2(8.0)$ & $2(13.3)$ & & \\
\hline Changed plan to a homebirth & $3(12.0)$ & $1(6.7)$ & & \\
\hline COVID did not change planned place of birth & $20(80.0)$ & $12(80.0)$ & & \\
\hline
\end{tabular}

${ }^{\mathrm{a}}$ Only asked of those planning an out-of-hospital birth

${ }^{b} p$-value of univariate OLS regression for continuous variales, Chi-squared test for dichotomous variables

${ }^{\mathrm{t}} p<0.10,{ }^{*} p<0.05,{ }^{* *} p<0.01,{ }^{* * *} p<0.001$

prenatal appointments, though more participants were unsure whether their providers had done so. Pregnant participants also sought care for health issues outside of pregnancy more often, and there was a trend toward participants scheduling extra prenatal appointments if concerned as well. We found only one difference in the frequency of childbirth concerns across waves: participants in the first wave reported more frequent worrying about not having access to a support person during their birth than those surveyed during the second wave (wave 1 mean $=2.2, \mathrm{SD}=1.3$; wave 2 mean $=1.8, \mathrm{SD}=1.4 ; \beta=$ $-0.39, p<0.001)$. Cumulative concerns about childbirth, however, were similar across data collection waves (Fig. 1A).

There was a trend toward considering having an outof-hospital birth more often during the first wave, as

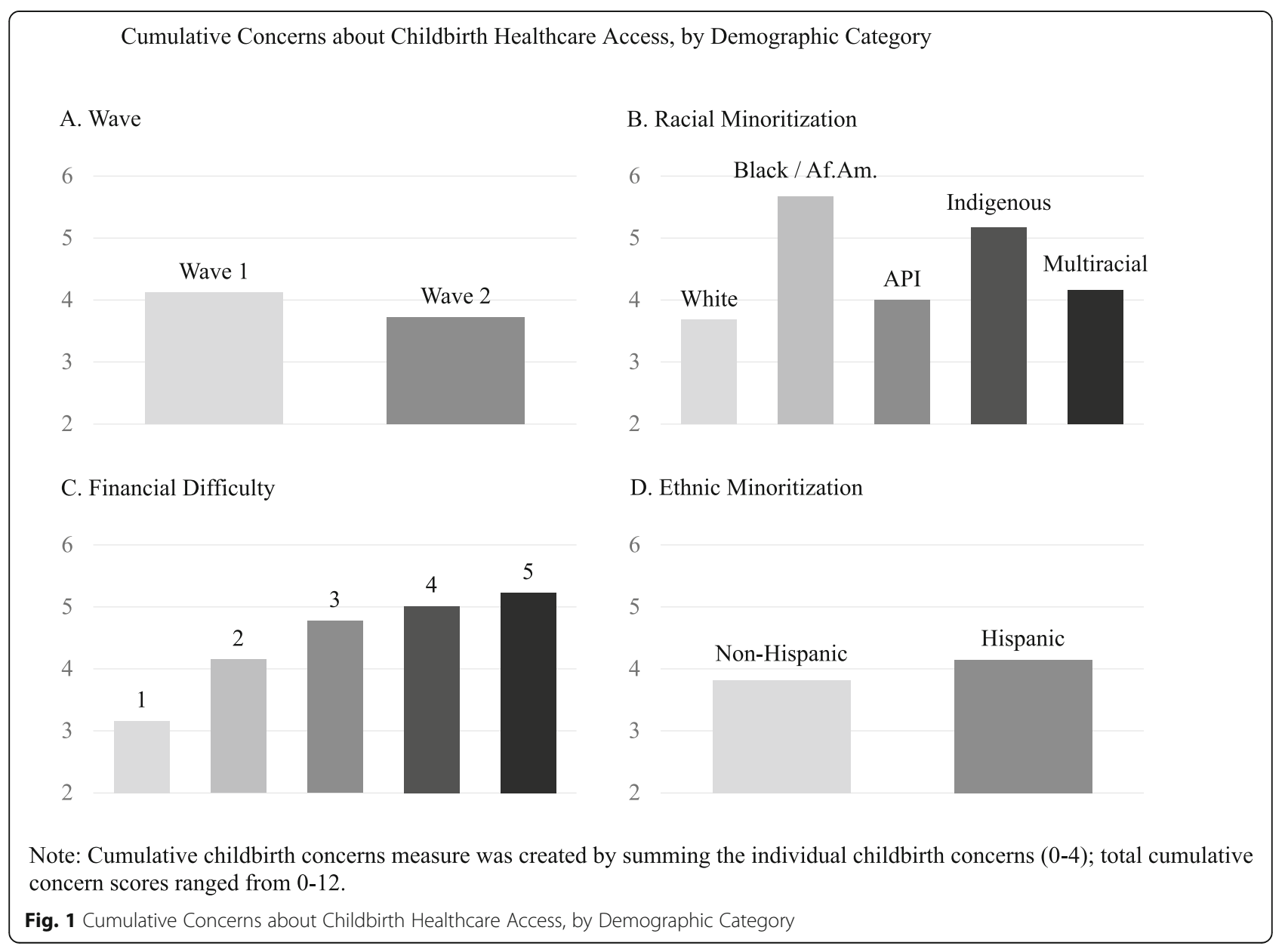


compared to the second wave, for these participants as well (wave 1 mean $=0.63, \mathrm{SD}=1.1$; wave 2 mean $=0.49$, $\mathrm{SD}=1.0 ; \quad \beta=-0.14, \quad p=0.061)$. However, rates of planned out-of-hospital birth remained statistically the same regardless of data collection wave (less than 10\% at each wave), as did reporting that COVID-19 had changed their plans for where to birth (20\% of those planning an out-of-hospital birth in both waves).

\section{Differences by racial/ethnic minoritization and financial insecurity}

Cross-sectional correlations by data collection wave showed that racial/ethnic minoritization and financial insecurity were significantly related to several perinatal healthcare access outcomes of interest (see Appendix Table 1 and 2). This was especially true for concerns regarding accessing healthcare at the time of childbirth: those who are racially or ethnically minoritized, and those who experienced acute financial insecurity, were more often concerned about having a support person available, having their provider available, and having access to adequate resources during childbirth.

Using multivariate ordinary least-squares (OLS) and logistic regressions (Table 3), we found that racial minoritization (broadly defined) did not have large or significant associations with perinatal healthcare access, concerns about access during childbirth, or considering / planning an out-of-hospital birth, with one exception: after controlling for financial insecurity, ethnic minoritization, age, urbanicity, parity, and essential worker status, racially minoritized participants (as compared to white participants) were more likely to worry about having access to equipment or resources during birth. However, when disaggregated by specific racial identity, a more complex picture emerged. Using a cumulative measure of all three childbirth concerns, we found that Black and Indigenous pregnant people, specifically, were more often concerned about accessing appropriate care when compared to those identifying as white, Asian or Pacific Islander, or multiracial (see Fig. 1B).

Ethnic minoritization (specifically, Hispanic identity) was significantly predictive of lower likelihood of seeking perinatal healthcare outside of pregnancy concerns and was associated with less worry about accessing equipment or resources during childbirth as compared to non-Hispanic participants. All other associations were not significant at the $p<0.05$ threshold. Further, differences by ethnic minoritization were not apparent in cumulative childbirth concerns (see Fig. 1D).

Finally, acute financial insecurity was significantly related to a number of indicators of lower perinatal healthcare access, after controlling for relevant demographic characteristics and racial/ethnic minoritization. Each unit increase in financial insecurity was predictive of a
$29 \%$ higher likelihood of reporting a reduced number of prenatal appointments. Increasing acute financial insecurity was significantly related to all three concerns about accessing healthcare during childbirth (Table 3), as well as the cumulative measure of childbirth concerns (Fig. 1C). Pregnant people with more financial insecurity also reported considering an out-of-hospital birth more often than those with fewer financial vulnerabilities. Each unit increase in financial insecurity was associated with a relatively small decrease in access, however (Cohen's D all between 0.10 and 0.20 standard deviations).

To explore whether these associations were similar across data collection waves, we also split the sample into wave $1(n=433)$ and wave $2(n=387)$ to conduct these multivariate regression-based analyses. These sensitivity analyses showed that over both waves, the magnitude and direction of the findings did not substantially differ. However, because of the significantly reduced sample sizes, significance levels of findings were diminished.

\section{Discussion}

The current study examined whether and how perinatal healthcare access for pregnant Californians has changed throughout the course of the COVID-19 pandemic. Specifically, we examined differences in access, concerns, and decision-making between 'non-surge' (summer) and 'surge' (winter) waves of data collection. Contrary to our hypothesis, we found that prenatal healthcare access remained the same or improved from an earlier, 'nonsurge' context to a later, 'surge' context. To place these data in context for California, in the previous year (2019) $78.7 \%$ of live births were to pregnant people who received adequate prenatal care, $12.1 \%$ were to pregnant people with intermediate care, and $9.1 \%$ were to pregnant people who received inadequate care [27]. During the winter surge, pregnant people also were less concerned about lacking a support person during childbirth, and thought about having an out-of-hospital birth less often, despite rapidly rising COVID-19 cases and hospitalizations in California. These unexpected results could reflect a number of contributing factors. In the first wave, we were still learning about the virus, including routes of viral transmission, and recommendations for the best and necessary mitigation strategies were mixed. By the second wave, science was clear on aerosol transmission as the primary vector. Accordingly, healthcare providers had better prevention strategies in place for both outpatient and inpatient clinical care. More effective treatments for COVID-19 infection were also available, perhaps reducing the initial fear associated with the virus. Another contributing factor to wave 2 findings may be that 9 months into the pandemic, respondents 
Table 3 Independent models predicting healthcare access, childbirth concerns, and childbirth decisionmaking $(n=820)$

\section{Predicting perinatal healthcare access}

\section{$\beta$ (Std. Err.)}

Difficulty paying bills

$0.16(.13)$

$-0.02(.05)$

I seek care for health issues outside pregnancy

Minoritization (POC)

$-0.11(.13)$

$-0.32(.14)$

$0.10(.06)$

AOR (Std. Err.)

Provider has begun remote visits

$\begin{array}{ll}\text { Minoritization (POC) } & 0.83(.15) \\ \text { Hispanic ethnicity } & 1.07(.21) \\ \text { Difficulty paying bills } & 1.06(.08) \\ \text { Provider has reduced number of prenatal visits } & \\ \text { Minoritization (POC) } & 0.75(.15) \\ \text { Hispanic ethnicity } & 0.82(.17) \\ \text { Difficulty paying bills } & 1.29(.1)\end{array}$

Predicting concerns about childbirth healthcare access

$\beta$ (Std. Err.)

I worry about missing support person during birth

$\begin{array}{ll}\text { Minoritization (POC) } & -0.02(.11) \\ \text { Hispanic ethnicity } & 0.07(.12) \\ \text { Difficulty paying bills } & 0.18(.05)\end{array}$

I worry about provider being unavailable during birth

$\begin{array}{ll}\text { Minoritization (POC) } & -0.13(.1) \\ \text { Hispanic ethnicity } & 0.01(.1) \\ \text { Difficulty paying bills } & 0.17(.04)\end{array}$

I worry provider won't have resources during birth

Minoritization (POC)

Hispanic ethnicity

Difficulty paying bills

Predicting childbirth decision-making

\section{$\beta$ (Std. Err.)}

I am thinking about not having my baby in a hospital

$$
\begin{array}{ll}
\text { Minoritization (POC) } & -0.01(.09) \\
\text { Hispanic ethnicity } & -0.13(.1) \\
\text { Difficulty paying bills } & 0.14(.04) \\
& \text { AOR (Std. Err.) }
\end{array}
$$

Planned out-of-hospital birth

$\begin{array}{lll}\text { Minoritization (POC) } & 1.14(.43) & 0.734 \\ \text { Hispanic ethnicity } & 0.43(.21) & 0.082 \\ \text { Difficulty paying bills } & 0.97(.16) & 0.850\end{array}$

0.006

0.028

0.922

0.163 $p$-value

0.617

0.233

0.740

Sig.

Cohen's D

0.415

0.067

p-value

0.311

0.710

0.451

0.158

0.342

$<0.001$

$p$-value

Sig.

Cohen's D

0.851

0.567

$<0.001$

***

$-0.02$

0.05

0.13

0.185

$-0.11$

0.899

0.01

$<0.001$

***

0.14

$<0.001$

**

$-0.22$

$-0.18$

**

0.17

$p$-value

Sig.

Cohen's D

$-0.01$

$-0.13$

$<0.001$

0.13

In addition to constructs of interest, all models control for maternal age, essential worker status, urbanicity, and parity

${ }^{t} p<0.10,{ }^{*} p<0.05,{ }^{* *} p<0.01,{ }^{* * *} p<0.001$ 
were experiencing 'pandemic fatigue', or the general demotivation to follow recommended precautions and restrictions. From a sampling perspective, reduced concerns over having a birth support person and reducing visits in wave 2 compared to wave 1 may simply reflect that wave 2 respondents were earlier in their pregnancies (e.g., first trimester), and so they did not have the same needs or worries that those later in pregnancy might report.

Prenatal healthcare access, concerns about childbirth, and childbirth decision-making were largely the same for racially and ethnically minoritized pregnant people as compared to white, non-Hispanic pregnant people in both 'surge' and 'non-surge' contexts, after controlling for other factors. However, that broader finding is contradicted, at least descriptively, when the 'racially minoritized' category is disaggregated further. Black and Indigenous pregnant people were far more concerned about accessing childbirth healthcare than white, Asian/Pacific Islander, and multiracial pregnant people. The finding that individuals from historically minoritized groups reported greater childbirth concerns is not surprising. Rather, our findings reflect the established research on poorer birth outcomes in these groups $[28,29]$. While maternal outcomes in general in the US rank lower than other developed countries [30], they are also worse in minoritized groups both in the US and globally [31-33]. Similarly, the pandemic has disproportionately affected people of color [34-39] and pregnant people of color $[24,40]$. The long-term impacts of these combined disparities on birthing people and their offspring should be a priority for future research, including tailoring care for this population to mitigate the effects. The magnitude of the difference in childbirth concerns for our sample is quite large for both Black and Indigenous respondents, at two-thirds and half of a standard deviation, respectively, when compared to white respondents. For Black respondents, for example, this is about the same magnitude of difference as comparing those who report a great deal of difficulty paying their bills as compared to those who report no difficulty. Moreover, these groups face significantly higher economic and healthcare-related stress, which studies have shown is exacerbated in the context of the pandemic [41]. Importantly, this finding is masked when simply comparing historically minoritized groups to non-minoritized populations. Despite having more than 800 participants across the two waves, we had insufficient sample size to test for statistically significant differences across sub-groups. Future research should investigate these findings further, including studies with larger samples and those focused solely on minoritized groups.
Finally, during both the summer lull and the winter surge, more financially insecure pregnant people were more likely to face barriers to prenatal healthcare access, more likely to be concerned about childbirth healthcare access, and considered having an out-ofhospital birth more often than those with more financial security. Our study underscores previous research that shows living at or below the poverty line is associated with worse prenatal care and maternal outcomes [42, 43]. This is especially concerning given that the pandemic has decreased financial security for many Californian pregnant people [44, 45], and, despite multiple federal COVID relief bills, it is clear that these financial strains are going to persist for several years [46].

Our findings should be considered within the context of important limitations. First, as previously noted, we did not have the sample sizes necessary to disaggregate all of the findings among subgroups. This is clearly critical in future research, especially in light of ongoing disparities in perinatal outcomes among historically minoritized groups. Additionally, this survey was selfreport and participants were recruited via social media. While the overall sample reflects the demographics of California (white alone $71.9 \%$, Black or African American alone 6.5\%, Asian/Pacific Islander 17.6\%, Two or More Races 4.0\%, Hispanic or Latino 39.4\%, White alone, not Hispanic or Latino 36.5\%) [47], and the survey was available in English and Spanish, there may be selection bias, and the sample cannot be considered representative of all pregnant people in the state or in the United States at large.

Despite these limitations, this study has important implications for healthcare providers and policymakers. As local, state, and federal governments continue to respond to the pandemic, it is clear that perinatal and birthing people - and subpopulations of perinatal and birthing people - should be considered a unique audience with specific needs and concerns that must be addressed. For example, when pregnant people first seek care, normalizing potential fears and then providing information about what to expect in clinic, during routine tests, and in the birth hospital that is specific to COVID prevention can help them to prepare, minimize potential concerns, and provide multiple opportunities over the course of pregnancy to ask questions. Likewise, as vaccine roll-out begins to include pregnant people, it will be critical to address the specific concerns of COVID-19 in pregnancy in order to facilitate uptake, especially among historically minoritized groups. Active efforts on the part of healthcare providers and healthcare systems to build trust in communities where they have done historical harm will be necessary to address what will likely be gaps in vaccination rates, which will only exacerbate 
existing disparities in COVID-19 morbidity and mortality $[41,48]$.

It is critical for healthcare providers and policymakers to continue focusing on addressing needs and gaps in care for historically minoritized subgroups [28, 49]. Even when overall levels of healthcare access in the two waves of our study improved over time, among Black participants, concerns over childbirth actually worsened. While the intersection of racism and perinatal morbidity and mortality certainly are on the radar for providers and policymakers, it is clear that Black and Indigenous pregnant people in our sample are experiencing more distress, possibly because rates of COVID-19 morbidity and mortality are higher in racially minoritized populations as well [41]. The combined stress of medical racism associated with birthing and COVID-19 must be addressed $[20,29]$. This may include more financial investments in provider groups that primarily serve Black and Indigenous communities, as well as support for services such as community doulas and native / Indigenous approaches to birthing, which have been shown to improve perinatal outcomes in these groups [50,51].

Lastly, as COVID relief bills attempt to address financial strain through lump sum payments, it is clear that this approach is insufficient to fill the gap that has resulted from months of poor economic conditions and recession associated with the pandemic [52]. Given that health care costs are the number one driver of financial strain, policy proposals aimed at improving healthcare coverage beyond the first year postpartum to all individuals all of the time (e.g., Medicare for All) can help to bridge the gap not only in perinatal healthcare access, but lifelong access especially among minoritized groups [53-56].

\section{Conclusion}

Despite surging COVID-19 cases and hospitalizations during the winter of 2020-2021, pregnant Californians generally enjoyed more access to, and fewer concerns about, their perinatal healthcare compared to those surveyed COVID-19 'lull' during the summer of 2020. However, across 'surge' and 'non-surge' pandemic circumstances, marginalized pregnant people continued to fare worse. This was especially true for those facing acute financial difficulty, and racially minoritized individuals identifying as Black or Indigenous. Targeting those communities for increased upstream healthcare supports - such as earlier access to vaccination, monetary investments in the healthcare structures that support these communities, and more direct financial relief to those facing the greatest economic insecurity - are promising avenues to blunt the negative impacts of the COVID-19 pandemic on pregnant people in California.
Abbreviations

SARS-CoV-2: Severe acute respiratory syndrome coronavirus 2; COVID-

19: Coronavirus disease 2019; CDC: Center for Disease Control and Prevention; WHO: World Health Organization; POC: People of color; OLS: Ordinary least-squares

\section{Supplementary Information}

The online version contains supplementary material available at https://doi. org/10.1186/s12884-021-03942-y.

Additional file 1. Participant Questionnaire.

Additional file 2 Appendix Table 1. Correlations between

minoritization, financial strain, healthcare access, childbirth concerns, and childbirth decision-making (June-July 2020).

Additional file 3 Appendix Table 2. Correlations between

minoritization, financial strain, healthcare access, childbirth concerns, and childbirth decision-making (December 2020-January 2021).

\section{Acknowledgements}

The authors thank Sharon Tafolla, who assisted with translation of the survey into Spanish and Nikita Satish for assisting with literature review and editorial assistance.

\section{Authors' contributions}

$L A S, J P$, and MW conceptualized the study. MW analyzed and interpreted the participant data and was a major contributor in writing the manuscript. LAS and JP were major contributors in writing and revising the manuscript. All authors read and approved the final manuscript.

\section{Funding}

Funding for the current study was provided by Hatch Project \#CA-D-HCE2582-H, Addressing Multifactorial Influences on Pregnancy Outcomes to Promote Health Equity. Funding for Dr. Whipps was provided by 5R01NR017659 (Simmons Pl).

\section{Availability of data and materials}

The datasets generated and/or analyzed during the current study are not publicly available due to ongoing analyses but are available from the corresponding author on reasonable request.

\section{Competing interests}

The authors declare no competing interests.

Received: 1 March 2021 Accepted: 1 June 2021

Published online: 02 July 2021

\section{References}

1. Levesque JF, Harris MF, Russell G. Patient-centered access to health care: conceptualising access at the interface of health systems and populations. Int J Equity Health. 2013;12:1-9. https://doi.org/10.1186/1475-9276-12-18.

2. Runkle JD, Brock-Martin A, Karmaus W, Svendsen ER. Secondary surge capacity: a framework for understanding long-term access to primary care for medically vulnerable populations in disaster recovery. Am J Public Health. 2012;102:e24-32. https://doi.org/10.2105/AJPH.2012.301027.

3. World Health Organization. WHO characterizes COVID-19 as a pandemic: World Health Organization; 2020. [Accessed: 14 May 2020]. Available from: https://www.who.int/emergencies/diseases/novel-coronavirus-2019/events-a s-they-happen

4. Petersen E, Koopmans M, Go U, Hamer DH, Petrosillo N, Castelli F, et al. Comparing SARS-CoV-2 with SARS-CoV and influenza pandemics. Lancet Infect Dis. 2020. https://doi.org/10.1016/S1473-3099(20)30484-9.

5. Johns Hopkins Coronavirus Resource Center. COVID-19 United States cases by county. Baltimore, MD: Johns Hopkins University; 2020. [Accessed: 18 December 2020]. Available from: https://coronavirus.jhu.edu/us-map

6. Paul R, Arif AA, Adeyemi O, Ghosh S, Han D. Progression of COVID-19 from urban to rural areas in the United States: a spatiotemporal analysis of prevalence rates. J Rural Health. 2020;36:591-601. https://doi.org/10.1111/ jrh.12486. 
7. Moreland A, Herlihy C, Tynan MA, Sunshine G, McCord RF, Hilton C, et al. Timing of state and territorial COVID-19 stay-at-home orders and changes in population movement-United States, march 1-may 31, 2020. Morb Mortal Wkly Rep. 2020;69:1198 Available from: https://dx.doi.org/10. 15585\%2Fmmwr.mm6935a2, 35, 1203, DOl: 10.15585/mmwr.mm6935a2.

8. Eby K. Coronavirus Timeline: Tracking Major Moments of COVID-19 Pandemic in San Francisco Bay Area. ABC7 News. 2020. [Accessed: 18 December 2020]. Available from: https://abc7news.com/timeline-of-corona virus-us-covid-19-bay-area-sf/6047519/

9. Dave D, Friedson Al, Matsuzawa K, Sabia JJ. When do shelter-in-place orders fight COVID-19 best? Policy heterogeneity across states and adoption time. Econ Inq. 2020;59:29-52. https://doi.org/10.1111/ecin.12944.

10. Friedson Al, McNichols D, Sabia JJ, Dave D. Shelter-in-place orders and public health: evidence from California during the COVID-19 pandemic. J Policy Analysis Manag. 2021;40:258-83. https://doi.org/10.1002/pam.22267.

11. Deliso M. California reports record for COVID-19 deaths as ICU bed availability falls. ABC News 2020. [Accessed: 18 December 2020]. Available from: https://abcnews.go.com/Health/california-reports-record-covid-19-dea ths-icu-bed/story?id=74790811.

12. COVID C. 19 (coronavirus disease): people with certain medical conditions. Cent Dis Control Prev. 2020; Accessed: 18 December 2020]. Available from: https://www.cdc.gov/coronavirus/2019-ncov/need-extra-precautions/ people-with-medical-conditions.html.

13. Woodworth KR, Olsen EO, Neelam V, Lewis EL, Galang RR, Oduyebo T, et al. Birth and infant outcomes following laboratory-confirmed SARS-CoV-2 infection in pregnancy-SET-NET, 16 jurisdictions, march 29-October 14, 2020. MMWR Morb Mortal Wkly Rep. 2020;69(44):1635. Available from: https://dx.doi.org/10.15585\%2Fmmwr.mm6944e2.

14. Partridge S, Balayla J, Holcroft CA, Abenhaim HA. Inadequate prenatal care utilization and risks of infant mortality and poor birth outcome: a retrospective analysis of 28,729,765 US deliveries over 8 years. Am J Perinatol. 2012;29(10):787. Available from: https://doi.org/10.1055/s-0032-131 6439-94.

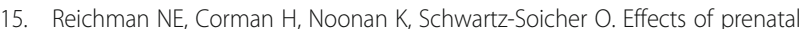
care on maternal postpartum behaviors. Rev Econ Househ. 2010;8:171-97 Available from: https://doi.org/10.1007/s11150-009-9074-5.

16. Brolin Ribacke KJ, Saulnier DD, Eriksson A, Von Schreeb J. Effects of the West Africa Ebola virus disease on health-care utilization-a systematic review. Front Public Health. 2016;4:222 Available from: https://doi.org/10.3389/ fpubh.2016.00222.

17. Moyer CA, Compton SD, Kaselitz E, Muzik M. Pregnancy-related anxiety during COVID-19: a nationwide survey of 2740 pregnant women. Arch Womens Mental Health. 2020:1-9 Available from: https://doi.org/10.1007/ s00737-020-01073-5.

18. Ravaldi C, Wilson A, Ricca V, Homer C, Vannacci A. Pregnant women voice their concerns and birth expectations during the COVID-19 pandemic in Italy. Women Birth. 2020. Available from: https://doi.org/10.1016/j.wombi. 2020.07.002.

19. Sahin BM, Kabakci EN. The experiences of pregnant women during the COVID-19 pandemic in Turkey: A qualitative study. Women Birth. 2020. Available from: https://doi.org/10.1016/j.wombi.2020.09.022. 34(2):162-9.

20. Davis-Floyd R, Gutschow K, Schwartz DA. Pregnancy, birth and the COVID19 pandemic in the United States. Med Anthropol. 2020;39:413-27 Available from: https://doi.org/10.1080/01459740.2020.1761804.

21. Bobrow E. A chaotic week for pregnant women in new York City. New Yorker; 2020.

22. Goer H. Dueling statistics: is out-of-hospital birth safe. J Perinat Educ. 2016; 25:75-9 Available from: https://dx.doi.org/10.1891\%2F1058-1243.25.2.75.

23. Hutton EK, Reitsma A, Simioni J, Brunton G, Kaufman K. Perinatal or neonatal mortality among women who intend at the onset of labour to give birth at home compared to women of low obstetrical risk who intend to give birth in hospital: a systematic review and meta-analyses. EClinicalMedicine. 2019;14:59-70. Available from: https://doi.org/10.1016/j. eclinm.2019.07.005

24. Gur RE, White LK, Waller R, Barzilay R, Moore TM, Kornfield S, et al. The disproportionate burden of the COVID-19 pandemic among pregnant black women. Psychiatry Res. 2020;293:113475. Available from: https://doi.org/10. 1016/j.psychres.2020.113475.

25. Feijen-de Jong El, Jansen DE, Baarveld F, van der Schans CP, Schellevis FG, Reijneveld SA. Determinants of late and/or inadequate use of prenatal healthcare in high-income countries: a systematic review. Eur J Pub Health. 2012;22:904-13 Available from: https://doi.org/10.1093/eurpub/ckr164.
26. US Census Bureau. American community survey demographic and housing estimates: California. 2018. Available from: https://data.census.gov/cedsci

27. National Center for Health Statistics, final natality data, Kotelchuck M. An evaluation of the Kessner Adequacy of Prenatal Care Index and a proposed Adequacy of Prenatal Care Utilization Index. Am J Public Health. 1994;84(9): 1414-20. [Accessed 16 April 2021]. Available from www.marchofdimes.org/ peristats. https://doi.org/10.2105/AJPH.84.9.1414.

28. Willis E, McManus P, Magallanes N, Johnson S, Majnik A. Conquering racial disparities in perinatal outcomes. Clin Perinatol. 2014;41:847-875. Available from: https://doi.org/10.1016/j.clp.2014.08.008.

29. Shah PS, Zao J, Al-Wassia H, Shah V. Knowledge synthesis group on determinants of preterm/LBW births. Pregnancy and neonatal outcomes of Aboriginal women: a systematic review and meta-analysis. Womens Health Issues. 2011;21:28-39 Available from: https://doi.org/10.1016/j.whi.2010.08.005.

30. Tikkanen R, Gunja MZ, Fitzgerald M, Zephyrin L. Maternal mortality and maternity Care in the United States Compared to 10 other developed countries. Commonwealth Fund Issue Briefs. 2020; Available from: https:// doi.org/10.26099/411v-9255.

31. Wang $E$, Glazer KB, Howell EA, Janevic TM. Social determinants of pregnancy-related mortality and morbidity in the United States: a systematic review. Obstet Gynecol. 2020;135(4):896-915 Available from: https://doi.org/10.1097/aog.0000000000003762.

32. Yaya $\mathrm{S}$, Yeboah $\mathrm{H}$, Charles $\mathrm{CH}$, Otu A, Labonte R. Ethnic and racial disparities in COVID-19-related deaths: counting the trees, hiding the forest. BMJ Glob Health. 2020;5(6):e002913 Available from: https://dx.doi.org/10. 1136\%2Fbmigh-2020-002913.

33. Shadmi E, Chen Y, Dourado I, Faran-Perach I, Furler J, Hangoma P, et al. Health equity and COVID-19: global perspectives. Int J Equity Health. 2020; 19(1):1-6 Available from: https://dx.doi.org/10.1186\%2Fs12939-020-01218-z.

34. Cyrus E, Clarke R, Hadley D, Bursac Z, Trepka MJ, Dévieux JG, et al. The impact of COVID-19 on African American communities in the United States. Health Equity. 2020;4(1):476-83 Available from: https://doi.org/10.1089/heq. 2020.0030 .

35. Millett GA, Jones AT, Benkeser D, Baral S, Mercer L, Beyrer C, et al. Assessing differential impacts of COVID-19 on black communities. Ann Epidemiol. 2020;47:37-44 Available from: https://doi.org/10.1016/j.annepidem.2020.05. 003.

36. Alcendor DJ. Racial disparities-associated COVID-19 mortality among minority populations in the US. J Clin Med. 2020;9(8):2442 Available from: https://doi.org/10.3390/jcm9082442.

37. Mackey K, Ayers CK, Kondo KK, Saha S, Advani SM, Young S, et al. Racial and ethnic disparities in COVID-19-related infections, hospitalizations, and deaths: a systematic review. Ann Intern Med. 2021;174(3):362-73 Available from: https://doi.org/10.7326/M20-6306.

38. Bibbins-Domingo K. This time must be different: disparities during the COVID-19 pandemic. Ann Intern Med. 2020;173(3):233-4 Available from: https://doi.org/10.7326/M20-2247.

39. Macias Gil R, Marcelin JR, Zuniga-Blanco B, Marquez C, Mathew T, Piggott DA. COVID-19 pandemic: disparate health impact on the Hispanic/Latinx population in the United States. J Infect Dis. 2020;222(10):1592-5 Available from: https://doi.org/10.1093/infdis/jiaa474.

40. Minkoff H. You Don't have to be infected to suffer: COVID-19 and racial disparities in severe maternal morbidity and mortality. Am J Perinatol. 2020; 37(10):1052-4 Available from: https://dx.doi.org/10.1055\%2Fs-0040-1713852.

41. Lund EM. Even more to handle: additional sources of stress and trauma for clients from marginalized racial and ethnic groups in the United States during the COVID-19 pandemic. Couns Psychol Q. 2020:1-10 Available from: https://doi.org/10.1080/09515070.2020.1766420.

42. Chou VB, Walker N, Kanyangarara M. Estimating the global impact of poor quality of care on maternal and neonatal outcomes in 81 low-and middleincome countries: a modeling study. PLoS Med. 2019;16(12):e1002990 Available from: https://doi.org/10.1371/journal.pmed.1002990.

43. Lindquist A, Kurinczuk JJ, Redshaw M, Knight M. Experiences, utilisation and outcomes of maternity care in England among women from different socio-economic groups: findings from the 2010 National Maternity Survey. BJOG. 2015;122(12):1610-7 Available from:https://doi.org/10.1111/1471-0528. 13059.

44. Molitor F, Doerr C. Peer Reviewed: Very Low Food Security Among LowIncome Households With Children in California Before and Shortly After the Economic Downturn From COVID-19. Prev Chronic Dis. 2021;18:200517 Available from: http://dx.doi.org/10.5888/pcd18.200517external icon. 
45. Food DGE. Tracking the COVID-19 Recession's effects on Food, housing, and employment hardships. Center on Budget and Policy Priorities 2020. [Accessed 18 April 2021]. Available from: https://www.jstor.org/stable/ resrep25613

46. Horowitz JM, Brown A, Minkin R. A year into the pandemic, Long-Term Financial Impact Weighs Heavily on Many Americans. Pew Research Center. 2021. [Accessed 18 April 2021]. Available from: https://www.pewresearch. org/social-trends/2021/03/05/a-year-into-the-pandemic-long-term-financialimpact-weighs-heavily-on-many-americans/

47. Bureau UC. QuickFacts. California: United States Census [Accessed 18 April 2021]. Available from: https://www.census.gov/quickfacts/fact/table/CA/ PST045219

48. Chen JT, Krieger N. Revealing the unequal burden of COVID-19 by income, race/ethnicity, and household crowding: US county versus zip code analyses. J Public Health Manag Pract. 2021;27:S43-56 Available from: https://doi.org/10.1097/PHH.0000000000001263.

49. Davis DA. Obstetric racism: the racial politics of pregnancy, labor, and birthing. Med Anthropol. 2019;38:560-73 Available from: https://doi.org/10. 1080/01459740.2018.1549389

50. Goode KL. Birthing, blackness, and the body: black midwives and experiential continuities of institutional racism [dissertation on the internet]. New York: The City University of New York; 2014. [Accessed: December 1, 2020]. Available from: https://academicworks.cuny.edu/gc_etds/423/

51. Kildea S, Tracy S, Sherwood J, Magick-Dennis F, Barclay L. Improving maternity services for indigenous women in Australia: moving from policy to practice. Med J Australia. 2016;205:374-9 Available from: https://doi.org/ 10.5694/mja16.00854.

52. Bitler M, Hoynes HW, Schanzenbach DW. The social safety net in the wake of COVID-19. Natl Bureau Econ Res. 2020; Available from: http://doi.org/10. 3386/W27796.

53. Elkins A. Moving towards Medicare for all: lessons from international singlepayer Systems for the United States [master's thesis on the internet]. Chapel Hill: University of North Carolina at Chapel Hill; 2018. [Accessed: December 1, 2020]. Available from: https://doi.org/10.17615/132m-7t48

54. Oberlander J. Lessons from the long and winding road to Medicare for all. Am J Public Health. 2019;109:1497-1500. Available from: https://doi.org/10. 2105/AJPH.2019.305295.

55. Blake V. Health care civil rights under Medicare for all. Hastings Law J. 2020; 72 Available from: https://ssrn.com/abstract=3554024.

56. Himmelstein DU, Lawless RM, Thorne D, Foohey P, Woolhandler S. Medical bankruptcy: still common despite the Affordable Care Act. Am J Public Health. 2019;109:431-3 Available from: https://doi.org/10.2105/AJPH.2018. 304901.

\section{Publisher's Note}

Springer Nature remains neutral with regard to jurisdictional claims in published maps and institutional affiliations.

Ready to submit your research? Choose BMC and benefit from:

- fast, convenient online submission

- thorough peer review by experienced researchers in your field

- rapid publication on acceptance

- support for research data, including large and complex data types

- gold Open Access which fosters wider collaboration and increased citations

- maximum visibility for your research: over $100 \mathrm{M}$ website views per year

At $\mathrm{BMC}$, research is always in progress.

Learn more biomedcentral.com/submissions 